\title{
Effects of Temperature on Circadian Clock and Chronotype: An Experimental Study on a Passerine Bird
}

\author{
Marina Lehmann, ${ }^{1}$ Kamiel Spoelstra, ${ }^{2}$ Marcel E. Visser, ${ }^{2}$ and Barbara Helm ${ }^{1,3}$ \\ 'Department of Biology, University of Konstanz and Max Planck Institute for Ornithology, Konstanz, Germany, ${ }^{2}$ Department of \\ Animal Ecology, Netherlands Institute of Ecology (NIOO-KNAW), Wageningen, The Netherlands, ${ }^{3}$ Institute of Biodiversity, \\ Animal Health and Comparative Medicine, Graham Kerr Building, University of Glasgow, Glasgow, UK
}

\begin{abstract}
Daily schedules of many organisms, including birds, are thought to affect fitness. Timing in birds is based on circadian clocks that have a heritable period length, but fitness consequences for individuals in natural environments depend on the scheduling of entrained clocks. This chronotype, i.e., timing of an individual relative to a zeitgeber, results from interactions between the endogenous circadian clock and environmental factors, including light conditions and ambient temperature. To understand contributions of these factors to timing, we studied daily activity patterns of a captive songbird, the great tit (Parus major), under different temperature and light conditions. Birds were kept in a light (L)-dark (D) cycle (12.5 L:11.5 D) at either $8^{\circ} \mathrm{C}$ or $18^{\circ} \mathrm{C}$ with ad libitum access to food and water. We assessed chronotype and subsequently tested birds at the same temperature under constant dim light $\left(\mathrm{LL}_{\mathrm{dim}}\right)$ to determine period length of their circadian clock. Thermal conditions were then reversed so that period length was measured under both temperatures. We found that under constant dim light conditions individuals lengthened their freerunning period at higher temperatures by $5.7 \pm 2.1 \mathrm{~min}(p=.002)$. Under $L D$, birds kept at $18^{\circ} \mathrm{C}$ started activity later and terminated it much earlier in the day than those kept under $8^{\circ} \mathrm{C}$. Overall, chronotype was slightly earlier under higher temperature, and duration of activity was shorter. Furthermore, individuals timed their activities consistently on different days under LD and over the two test series under $L L_{\text {dim }}$ (repeatability from .38 to .60 ). Surprisingly, period length and chronotype did not show the correlation that had been previously found in other avian species. Our study shows that body clocks of birds are precise and repeatable, but are, nonetheless, affected by ambient temperature. (Author correspondence: marina.lehmann@uni-konstanz.de)
\end{abstract}

Keywords: Activity patterns, Parus major, Phase, Period length, $\mathrm{Q}_{10}$, Repeatability, Temperature compensation, Timing

\section{INTRODUCTION}

As environments fluctuate substantially over the 24-h day, the scheduling of daily activities is thought to be closely linked to fitness. Being in time can give an advantage, e.g., in foraging for food, finding a mating partner, or escaping predators (Kronfeld-Schor \& Dayan, 2003; Moore \& Doherty, 2009; Sakai \& Ishida, 2001). Within a population, however, not every individual is on the same schedule, so that there is variation in timing traits such as phase angle difference relative to zeitgebers, such as sunrise or sunset. In humans, individual time patterns are relatively consistent and have a heritable component (Merrow et al., 2005; Roenneberg \& Merrow, 2007). Individuals can be classified into "chronotypes" (e.g., morning or evening types), although additional factors, such as age and social context, time of year, and ontogeny, also affect timing (Brown et al., 2008; Natale \& Di Milia, 2011; Roenneberg et al., 2007; Strang-Karlsson et al., 2010). Much less is known about consistency of chronotypes and other aspects of scheduling, e.g., onset and end of activity, in wild-derived animals. If timing was similarly consistent, as has been suggested in some studies (Bertin et al., 2007; Murphy et al., 2008), schedules should be under selection depending on relative costs and benefits. Specifically, selection should act on the mechanisms that regulate the expression of a given chronotype in a given environmental context.

One of the key factors that influences chronotype is the free-running period length $(\tau)$ of the underlying circadian clock, which is also known to differ within populations and between species (Daan \& Beersma, 2002, Helm \& Visser, 2010; Wyse et al., 2010). In many species, including humans (Allebrandt \& Roenneberg. 2008; Brown et al., 2008), mice (Dallmann et al, 2011), birds (Aschoff, 1965; Aschoff \& Wever, 1962, 1966), and insects (Fleury et al., 2000), chronotype correlates with

Address correspondence to Marina Lehmann, Department of Biology, University of Konstanz, PO Box 616, 78457 Konstanz, Germany; Email: marina.lehmann@uni-konstanz.de 
$\tau$ (Aschoff \& Pohl, 1978), such that an individual with a fast clock $(\tau<24 \mathrm{~h})$ would be an early chronotype. However, there are also examples for an absence of such a relationship, possibly due to additional factors that could modify entrainment and weaken the correlation (Brown et al., 2008; Fleissner \& Fleissner, 2002; Helm \& Visser, 2010; Shimizu \& Masaki, 1997). Besides light, one aspect of the natural environment that shapes schedules is ambient temperature (Aschoff, 1979; DeCoursey, 1960; Redlin, 2001; Rensing \& Ruoff, 2002; Sweeney \& Hastings, 1960). Temperature can affect timing directly, as seen by modified activity patterns and behavior in response to changing thermal conditions (DeCoursey, 1960; Vivanco et al., 2010). In addition, temperature could affect timing by modifying the underlying circadian period length. A rise in temperature increases the reaction rate of most biochemical processes (Ruoff \& Rensing, 2004), so that the ratio of two reactions measured at temperatures that differ by $10^{\circ} \mathrm{C}$ (i.e., the so-called " $\mathrm{Q}_{10}$ ") is usually $\sim 2-3$. In contrast, however, the circadian clock is largely temperature-compensated (Merrow et al., 2005), i.e., its period length stays roughly the same over a range of ambient temperatures. Correspondingly, a $Q_{10}$ of $\sim 1$ is characteristic of circadian processes (Rensing \& Ruoff, 2002). However, temperature compensation is not perfect. A number of studies on endotherms and ectotherms report change of period length dependent on ambient temperature (Aschoff, 1979; Pohl, 1968; Sweeney \& Hastings, 1960) (Supplementary Table 1 ). $Q_{10}$ values are within a range of .85-1.4 which implies up to $40 \%$ differences in cycle length for a difference of $10^{\circ} \mathrm{C}$. According to some studies, e.g., on chaffinches, differences in period length of that magnitude can strongly influence activity timing under light-dark cycles (Aschoff \& Wever, 1966). If similar temperature-dependent changes of the clock occurred in the wild, this could thus be highly relevant for fitness. Therefore, a better understanding of temperature effects on timing under constant and synchronizing conditions could be an important step towards clarifying the role of circadian clocks for timing in the "real world" (Menaker, 2006).

Herein, we investigate the effects of normally experienced temperatures (Gosler, 1993) on $r$ and chronotype in a species with a relatively well-known ecology. Great tits (Parus major) are widespread songbirds whose behavior has also been studied with regard to temporal patterns (Bednekoff \& Houston, 1994; Charmantier et al., 2008; Hinde, 1952; Kacelnik \& Krebs, 1982; Nussey et al., 2005; Ydenberg, 1984). As in other birds, male great tits are more successful at defending their territory and attracting females by singing early in the day, and thereby produce more offspring (Daan \& Aschoff, 1982; Dolan et al., 2007; Murphy et al., 2008; Poesel et al., 2007). In related blue tits (Cyanistes caeruleus), early-singing males gained fitness via extra-pair offspring (Kempenaers et al., 2010; Poesel et al., 2007). Thus, an early chronotype, and possibly a correspondingly short $\tau$, may be advantageous. A previous study examined a large number of individuals of a great tit population and found an average $\tau$ of $23.8 \mathrm{~h}$ (Helm \& Visser, 2010). Females seemed to prefer males with a fast clock for extra-pair matings, all the more if their social mate had a siower clock, which would be consistent with links between fast clocks and early chronotypes. The present follow-up study aims at examining the still poorly understood links between circadian clock, chronotype, and ambient temperature. To investigate these links, we subjected birds from a wild population to two temperature treatments $\left(8^{\circ} \mathrm{C}\right.$ and $\left.18^{\circ} \mathrm{C}\right)$. We also tested whether chronotype was consistent within individuals (i.e., repeatable), and whether it correlated with circadian period length by keeping the same birds under a light (L)-dark (D) cycle and constant dim light $\left(L L_{\text {dim }}\right)$. We found an effect of temperature on $\tau$ as well as on activity schedules, but no correlation between $\tau$ and chronotype. High repeatability confirmed chronotype is a consistent trait in these birds, at least under captive conditions.

\section{METHODS}

Birds used for the experiments were 24 male great tits that were obtained from a long-term study population at Hoge Veluwe (The Netherlands) (Helm \& Visser, 2010). The birds were taken in and hand-raised during the breeding season of 2009 . Family size varied from single birds to up to four brothers. Because of earlier suggestions that paternity could be related to clock properties, we scrutinized relatedness by molecular genetic analysis (Helm \& Visser, 2010). We found no indication of extrapair offspring (i.e., there were no half-siblings in the set of birds). During the experiment, birds were kept in 24 separate indoor aviaries $(2 \times 2 \times 2.25 \mathrm{~m})$. For the entire duration of the experiment, each bird was thereby individually recorded in its own aviary. It had previously been shown by spatial autocorrelation that social effects on timing between neighboring birds were absent (Helm \& Visser, 2010). Birds received fresh water and were fed ad libitum with a constant daily amount of food, consisting of a mixture of minced beef, proteins, and vitamins, complemented by sunflower seeds, fat balls, a mix of dried insect, and calcium and mineral supplements.

The studied birds had previously been used in an experiment on the effect of temperature on the timing of reproduction from December 2009 to September 2010 (see Schaper et al., 2012) and were then kept at $8^{\circ}$ $\mathrm{C}$ except for a 5 -d warmer period $\left(18^{\circ} \mathrm{C}\right)$ for one group. Our experiment started on 13 November 2010 and ended on 28 December 2010. We divided the birds into two groups experiencing ambient temperatures in the aviaries of either $8^{\circ} \mathrm{C}$ or $18^{\circ} \mathrm{C}$, such that each new group consisted of a similar number of birds from the earlier experimental groups. Temperature treatments were alternated between neighboring aviaries (Figure 1).

At the start of the experiment, all birds were kept under a daily light:dark regime of $12.5 \mathrm{~L}: 11.5 \mathrm{D}$ for $17 \mathrm{~d}$ 


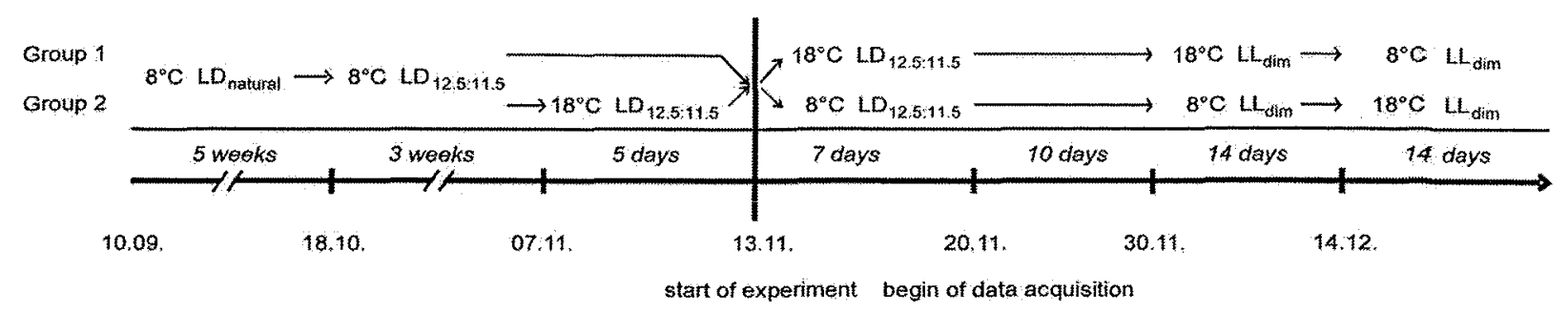

FIGURE 1. Experimental set up of light and temperature conditions. Birds were kept for $10 \mathrm{~d}$ under a daily $12.5 \mathrm{~L}: 11.5 \mathrm{D}$ regimen at either $8^{\circ}$ $\mathrm{C}$ or $18^{\circ} \mathrm{C}$. Afterwards, the light was set to constant dim light $\left(\mathrm{LL}_{\mathrm{dim}}\right)$, and temperatures stayed the same for $14 \mathrm{~d}$. For another $14 \mathrm{~d}$ under $\mathrm{LL}_{\text {dim }}$, temperature settings were crossed over between groups.

(Figure 1). The main light sources were three highfrequency fluorescent tubes. At night, a small green lamp provided dim light of .5 lux at perch level. After 1 wk of habituation, we recorded activity for $10 \mathrm{~d}$ to assess onset and offset of activity and thereby chronotype (LD experiment). The light condition was then changed to constant dim light $\left(\mathrm{LL}_{\mathrm{dim}}\right)$, whereby, until the end of the study, the night lamp was used as sole illumination (Figure 1). Thereby, we measured the free-running period under the temperatures to which birds had been pre-exposed. Two weeks after the shift to $L_{\mathrm{dim}}$ conditions, temperatures were changed in a crossover design from $8^{\circ} \mathrm{C}$ to $18^{\circ} \mathrm{C}$, or from $18^{\circ} \mathrm{C}$ to $8^{\circ} \mathrm{C}$, respectively, for a second 2-wk series of measurements under $L_{\mathrm{dim}}$ (Figure 1). Thus, the free-running period of each bird was measured under both temperature conditions, but in a different sequence. Light and temperature conditions were set and monitored for each individual aviary. Based on sensor recordings, temperatures fluctuated by $\pm 1-2^{\circ} \mathrm{C}$ around the set point. Intensity of the constant dim light was measured once in each aviary for each temperature condition. Although light intensity varied from .4 to .8 lux between aviaries, it was unrelated to ambient temperature. During the $\mathbf{L L}_{\mathrm{dim}}$ experiment, we avoided food entrainment by feeding birds at randomized times. Exact feeding times were noted for subsequent data correction.

For activity monitoring, we used radar detectors (Conrad Electronics, Hirschau, Germany). One detector per aviary recorded movements of the single bird for subsequent computer storage (Helm \& Visser, 2010). These radar detectors use the Doppler principle to record even small movements by sending out a signal in the microwave range that is reflected by the bird. Superimposing the reflected over the original signal then reveals information about the speed and proximity of the bird relative to the sensor. Any number of bird movements within a 2-s interval was counted as activity, and the total number of 2-s intervals containing activity was stored every 2 min (i.e., a number between 0 and 60 ). In parallel to movements, temperature and light information (on/off) was recorded as well.

All activity caused by feeding the birds or measuring light intensity was removed before data analysis by marking it as missing values. Birds responded to changes in light condition from $L D$ to $L L_{\text {dim }}$ initially by irregular activity patterns. Therefore, the first $5 \mathrm{~d}$ of activity were not used for determination of period length $(\tau)$. For the same reason, the first $2 \mathrm{~d}$ of data after switching of temperatures were excluded from analysis. Two additional days of data were excluded for one bird at the start of the first temperature treatment $\left(L L_{d i m l}\right)$ and of another one at the end of the second temperature treatment $\left(\mathrm{LL}_{\mathrm{dim} z}\right)$. Both birds showed an abrupt change in behavior, probably due to external disturbance. Because of sensor malfunction during $L D$, one bird had to be removed from the chronotype analysis; for another there was no activity information available.

To calculate $\tau$, we used Lomb-Scargle periodogram analysis (Ruf, 1999), implemented in the software program ChronoShop (Spoelstra, 2010). $\tau$ was estimated from $9 \mathrm{~d}$ of data for the first temperature treatment and from $13 \mathrm{~d}$ of data for the second temperature treatment. These time series are long enough to allow stable estimates of $\tau$ (Helm \& Visser, 2010). For estimation of timing patterns under $\mathrm{LD}$, we used measurements derived from $10 \mathrm{~d}$ of data.

Depending on the individual bird, the activity-onset was either a sudden event or a drawn-out increase in activity. The same was true for activity-offset with even greater variation. We used an edge detector (Helm \& Gwinner, 2005) to determine the time of greatest increase in activity in the morning (within $1 \mathrm{~h}$ before and after lights-on, respectively) and of greatest decrease in activity in the evening (within $2 \mathrm{~h}$ before and after lights-on, respectively) for each bird. This method allows separating the main activity interval from recurring lesser increases and decreases in activity, yielding a relatively late calculated activity-onset and early activity-offset. Duration of activity was the interval between activityonset and activity-offset. Chronotype was calculated as a bird's mid-activity (midpoint between activity-onset and activity-offset) relative to mid-light-time (mid-time between lights-on/lights-off). An early chronotype is thereby characterized by a positive phase angle difference (i.e. phase advance) between midpoint of activity and mid-light-time, whereas a negative phase angle difference indicates a late (i.e. phase-delayed) chronotype. 
The derived timing parameters were analyzed by linear mixed models using restricted maximumlikelihood estimation methods (Genstat, 1993). This approach implements a repeated-measures design in all cases to take account of the individuals that were measured multiple times. Effects of temperature treatment and $t$ were modeled as fixed factors and covariates for chronotype as response variable. For $\tau$ as response variable, temperature treatment and trial (first vs. second treatment) were included as fixed factors. The interaction between these factors was included to test for carry-over effects, i.e., to investigate whether $\tau$ was influenced by sequence of treatments. Effects of family and individual were usually included in the model as random effects, except for analyses in which we modeled them as fixed factors for significance testing (Genstat, 1993). Significance levels were derived from Wald statistics that asymptotically follow a $\chi^{2}$ distribution. As significance levels can depend on the order of factors within the model, we tested each factor by removing as well as adding it to the model. Usually sequence of entrance did not affect results; but, if it did, we always used the most conservative outcome. We progressively reduced models until only factors were retained that had significant effects on timing; in all cases, the reported statistics for each factor are derived from the most parsimonious model. Estimates of repeatability followed the analysis of variance (ANOVA)-based procedure suggested by Lessells and Boag (1987), using the ANOVA and LM (linear models) function from the stats package implemented in the software package $R$ ( $R$ Development Core Team, 2012). Data were tested for deviation from normality, and specifically for heteroscedasticity between temperature groups using Bartlett's test. In some cases, data were not normally distributed and had heterogeneous variances (Genstat, 1993). If heteroscedasticity was detected, we added corresponding analyses after rank transformation (Conover \& Iman, 1981). Data were also characterized by descriptive methods (mean $\pm S D$ ) and by nonparametric tests.

All experiments were conducted under license of the Animal Experimental Committee of the KNAW (DEC protocol no. NIOO 10.12) and in accordance with international ethical standards (Portaluppi et al., 2010).

\section{RESULTS}

Birds Under LD Cycles (LD)

On average, the chronotype, as defined by the midpoint of activity, preceded mid-light-time by $13.5 \pm 1.35 \mathrm{~min}$ (mean \pm SEM; $\mathrm{n}=217$ observations from 22 birds) (Figures 2 and 3). Onset of activity, as estimated by an edge detector as the time of greatest increase in activity, occurred $5.9 \pm 1.26 \mathrm{~min}$ after lights-on, and completion preceded lights-off by $33.0 \pm 2.50 \mathrm{~min}$ (Figures 2 and 3 ).

Linear mixed-model analysis revealed significant effects of temperature on chronotype $\left(\right.$ Wald $_{1}=5.12$, $p=.024$; Figure 2, Table 1), with a tendency for birds to show a slightly earlier chronotype if kept under higher temperatures. However, because there was an indication of heteroscedasticity (Bartlett's test: $\chi^{2}=4.31, d f=1$, $p=.038$ ), we also used a more conservative approach over ranks, for which significance levels depended on the sequence of factors in the analysis (most conservative Wald $_{1}=2.98, p=.084$; Table 1). In the evening, activity ended much earlier under warmer than under colder temperatures $\left(\right.$ Wald $_{1}=16.30, p<.001$; Table 1$)$. Conversely, in the morning, birds under warmer temperatures were active a bit later (Wald $_{1}=4.41, p=.065$ [most conservative statistic]; Table 1), so that, overall, the activity period was shortened under warm temperatures $\left(\mathrm{Wald}_{1}=5.97, p=.015\right.$; Figure 2, Table 1). The effect of temperature on chronotype derived from a greater advancing effect of temperature on activity-offset compared to that on activity-onset. All activity patterns showed clear consistency between the repeated recordings of individuals, as indicated by significant effects of individual on all parameters of timing $(p<.001$; Figure 3, Table 1). Overall, differences between individuals were associated with a much larger proportion of variance than differences between temperature treatments (activity-onset: individual $36.3 \%$, treatment $4.9 \%$, residual $58.8 \%$; activity-offset: individual $32.4 \%$, treatment $10.3 \%$, residual $57.3 \%$; activity duration: individual
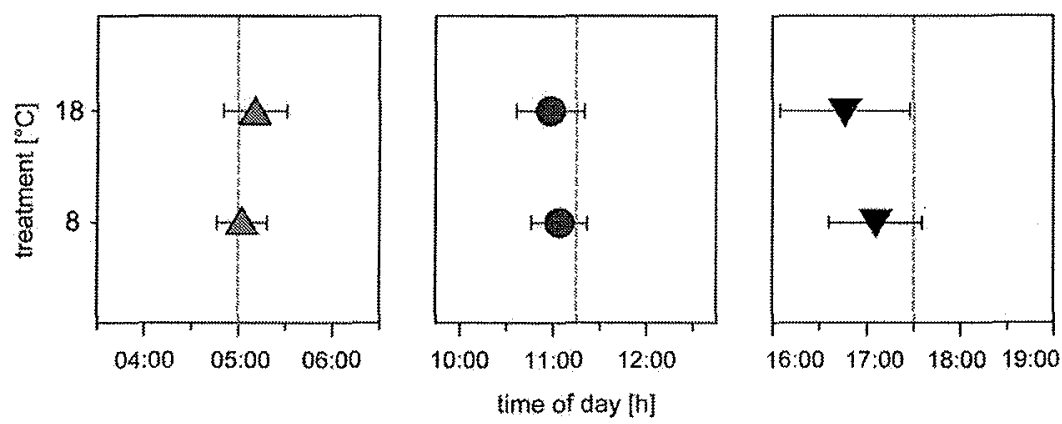

FIGURE 2. Activity timing of great tits under two temperature conditions. Data points show onset (triangles), midpoint (circles), and offset (inverted triangles) of activity in relation to lights-on, mid-day, and lights-off (dashed lines), respectively. Error bars indicate standard deviation; $n$ is the total number of measurements collected from the 22 birds $\left(n_{\text {onset }}=217, n_{\text {midpoint }}=217, n_{\text {offser }}=217\right)$. 


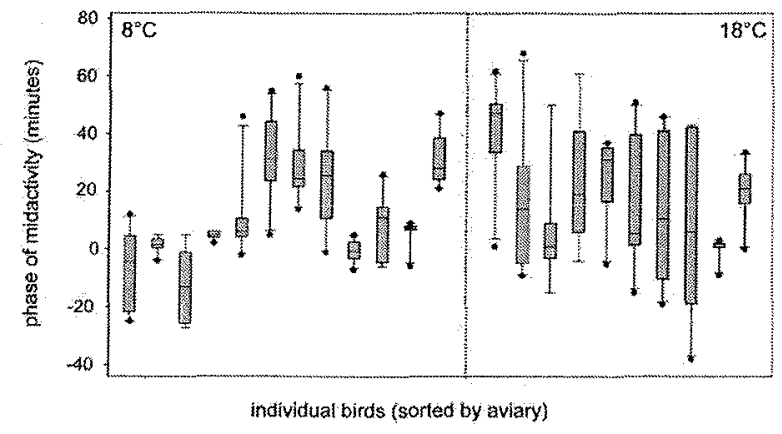

FIGURE 3. Variation in chronotype under LD (defined as difference of midpoint of activity from mid-day in minutes). Boxplots summarize all recorded activities of each individual. Error bars above and below the box indicate the 90th and 10th percentiles; dots indicate outliers. Positive values represent birds whose activity preceded mid-light-time. Boxplots are sorted by temperature treatment and aviary number; $n$ is the total number of measurements collected from the 22 birds $(n=217)$.

$27.9 \%$, treatment $16.6 \%$, residual $55.5 \%$; chronotype: individual $39.7 \%$, treatment $.3 \%$, residual $60.0 \%$ ).

Repeatability was calculated by ANOVA for a total sample size of 22 birds with $10 \mathrm{~d}$ of data in each case and ranged between .38 and .45 , depending on timing parameter and method of calculation (i.e., raw data vs. ranks; Table 2).

\section{Birds Under Constant Dim Light ( $\left.L_{\text {dim }}\right)$}

Circadian period length $\tau$ for all 24 birds was on average $23.77 \pm .18 \mathrm{~h}$ (range: $23.33-24.07 \mathrm{~h}$; skewness: $-.66 \pm .34$; kurtosis: $-.79 \pm .67 ; \mathrm{n}=48$, for individual actograms, see Supplementary Figure 1) and differed significantly from 24 h (Wilcoxon: $W_{48}=\mathbf{5}, p<.001$ ). Figure 4 shows the period lengths of all birds for the two temperature treatments. Ambient temperature had a clear lengthening effect on $\tau\left(\right.$ Wald $\left._{1}=10.01, p=.002, n=48\right)$. There was no difference between the two trials ( Wald $_{1}=2.07, p=.150$, $n=48$ ), and nor were there effects of sequence of treatment $\left(8^{\circ} \mathrm{C}\right.$ to $18^{\circ} \mathrm{C}$ or vice versa; Wald $_{1}=2.33, p=.127$, $\mathrm{n}=48)$. Period length was longer at $18^{\circ} \mathrm{C}(23.81 \pm .17 \mathrm{~h}$, range: $23.47-24.07 \mathrm{~h} ; \mathrm{n}=24)$ compared to at $8^{\circ} \mathrm{C}(23.72$ $\pm .2 \mathrm{~h}$, range: $23.33-23.93 \mathrm{~h} ; \mathrm{n}=24$ ). Nevertheless, the $\mathrm{Q}_{10}$ value was extremely close to $1(1.004 \pm .0074$ [mean $\pm S D$ ]; $n=24$ ). We found no evidence for an influence of period length on chronotype $\left(\right.$ Wald $_{1}=.01, p=.918, \mathrm{n}=$ 20). Period length was significantly different between individuals ( Wald $_{23}=76.18, p<.001, n=48$; Figure 4) and highly repeatable within an individual over both treatments (between .53 and .60; Table 2).

\section{DISCUSSION}

We show that change in ambient temperature had an effect on both $\tau$ and on entrained schedules of great tits. Birds had clocks, on average, that, were faster than $24 \mathrm{~h}$, and chronotypes that were slightly early in comparison to the mid-light-time. Repeatability of individual patterns indicated consistent daily timing, but we did not detect a correlation between $\tau$ and chronotype. $\tau$ was on average $<24 \mathrm{~h}$ and was close to the previously determined estimate from the same population (Helm \& Visser, 2010). In the previous study, birds were kept at $\sim 20^{\circ} \mathrm{C}$ and had a mean $\tau$ of $23.83 \mathrm{~h}$. This value is almost identical to the mean $\tau$ reported here for birds kept under $18^{\circ} \mathrm{C}(23.81 \mathrm{~h})$.

Higher ambient temperatures had a significant lengthening effect on $\tau$ (Figure 4). Usually, higher temperature increases the speed of biochemical reactions, whereas circadian clocks are largely temperature-compensated. In our study, the circadian clock was mostly temperature-compensated, but the longer $\tau$ suggested that biochemical processes underlying the clock were in fact slightly slowed. This slowing effect is, however, barely reflected in the $Q_{10}$, as it is the ratio of the two period lengths taken at the different temperatures. $Q_{10}$ values are known to vary between species. For example, in lizards, bats, or mice, temperature effects seemed to be greater than in birds (Sweeney \& Hastings, 1960). In comparison to some other species, the $\mathrm{Q}_{10}$ of 1.004 reported here shows almost perfect temperature compensation (Supplementary Table 1). The $Q_{10}$ for

TABLE 1. Effect of temperature and individual on activity timing (Wald test)

\begin{tabular}{|c|c|c|c|c|c|c|c|c|c|}
\hline \multirow[b]{2}{*}{ Variable } & \multirow[b]{2}{*}{$\mathrm{n}$} & \multicolumn{4}{|c|}{ Temperature } & \multicolumn{4}{|c|}{ Individual } \\
\hline & & Wald $_{1}$ & $p$ & Wald $_{1}$ on ranks & $p$ on ranks & Wald $_{20}$ & $p$ & Wald $_{20}$ on ranks & $p$ on ranks \\
\hline Onset & 217 & 10.07 & .002 & 3.41 & .065 & 92.70 & $<.001$ & 114.05 & $<.001$ \\
\hline Offset & 217 & 19.51 & $<.001$ & 16.30 & $<.001$ & 86.88 & $<.001$ & 86.75 & $<.001$ \\
\hline Duration & 217 & 5.97 & .015 & - & - & 78.49 & $<.001$ & - & - \\
\hline \multirow[t]{2}{*}{ Chronotype } & 217 & 5.12 & .024 & 2.98 & .084 & 98.88 & $<.001$ & 116.67 & $<.001$ \\
\hline & & WaId $_{1}$ & $p$ & Wald $_{2}$ on ranks & $p$ on ranks & Wald $_{23}$ & $p$ & Wald $_{23}$ on ranks & $p$ on ranks \\
\hline Period length $(\tau)$ & 48 & 6.97 & .008 & 10.01 & .002 & 60.87 & $<.001$ & 76.18 & $<.001$ \\
\hline
\end{tabular}

Temperature had an effect on time of onset, offset, and duration of activity, as well as on chronotype (midpoint of activity) under LD and an effect on period length $\tau$ under LL conditions. All values were highly consistent within individuals. Parameters that were not normally distributed were also analyzed over rank-transformed data. Degrees of freedom are indicated by subscripts; $n$ indicates the total number of measurements collected from the 22 birds. 
TABLE 2. Repeatability of activity timing, chronotype (midpoint of activity), and period length \pm SEM

\begin{tabular}{lccccc}
\hline Variable & $\mathrm{n}$ & Repeatability & $\mathrm{F}, d f_{\text {num }}, d f_{\text {den }}$ & Repeatability ranks & $\mathrm{F}, d f_{\text {num }}, d f_{\text {den }}$ \\
\hline Onset & 217 & $.395 \pm .09^{* * *}$ & $7.50,21,195$ & $.452 \pm .09^{* * *}$ & $9.20,21,195$ \\
Offset & 217 & $.397 \pm .09^{* * *}$ & $7.54,21,195$ & $.384 \pm .09^{* * *}$ & $7.17,21,195$ \\
Duration & 217 & $.399 \pm .09^{* * *}$ & $7.55,21,195$ & - & - \\
Chronotype & 217 & $.397 \pm .09^{* * *}$ & $7.51,21,195$ & $.436 \pm .09^{* * *}$ & $8.63,21,195$ \\
Period length $\left(\tau, L L_{\text {din }}\right)$ & 48 & $.528 \pm .15^{*}$ & $3.23,24,23$ & $.604 \pm .13^{* *}$ & $4.05,24,23$ \\
\hline
\end{tabular}

Data for onset and end of activity and for period length were not normally distributed, and repeatability was calculated over ranks as well. For period length, temperature was included in the ANOVA model as a covariate. Asterisks denote significance levels for repeatability in the respective ANOVA models $\left({ }^{*} p<.05,{ }^{* *} p<.01,{ }^{* * *} p<.001\right)$; $n$ indicates the total number of measurements collected from the 22 birds; $d f_{\text {num }}$ $=$ numerator degrees of freedom; $d f_{\text {den }}=$ denominator degrees of freedom.

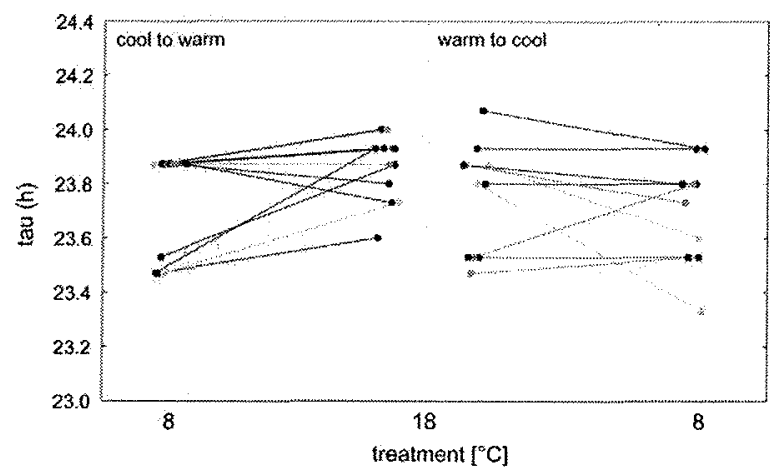

FIGURE 4. Change of period length $\tau$ in individual birds due to temperature treatments. Overall, period length increased when temperatures rose and decreased when temperatures dropped. Lines connect the values of a given bird $\left(n_{\text {cool to warm }}=13, n_{\text {warm }}\right.$ to cool $=11$ ).

other songbird species (finches) was also close to 1 $(\sim .99)$, and thereby almost completely temperaturecompensated (Enright, 1966; Pohl, 1968, 1974). However, the effects of temperature on even a very well compensated clock could be larger under natural conditions where individuals experience a much broader range of temperatures than the tested $10^{\circ} \mathrm{C}$ difference.

The advancing effect of warmer temperature on chronotype was relatively small ( $.3 \%$ of variance) (Figure 2). This could be partly due to the fact that each bird under $L D$ experienced only one temperature treatment, which reduced sample size and allowed comparison of chronotype only between groups but not within individuals. Another possible reason for the overall small effect is the method of calculating chronotype. We defined chronotype as the midpoint between onset and termination of activity in relation to the mid-lighttime, so that changes in morning and evening behavior partly offset each other. However, a closer look at the activity patterns reveals that activity-offset depended more strongly on ambient temperature than activityonset. There is also a difference in variability of the two values, apart from temperature effects, which is much higher for the completion than for the onset of activity (Daan \& Aschoff, 1975) (Figure 3). A similar pattern has been noted in free-living great tits, for which seasonal variation was low for awakening times but substantial for roosting times (Hinde, 1952). The greater sensitivity to temperature of activity-offset in comparison to activity-onset adds to the idea of more rigidly controlled timing in the morning. For a bird like the great tit, which prefers to sleep in cavities or sheltered places with low light levels, it is particularly important to anticipate the right time for rising. Most important activities happen in the morning when territories are defended, females are attracted, and mating takes place (Hinde, 1952; Kacelnik \& Krebs, 1982; Poesel et al., 2007). In contrast, in the evening the birds can perceive light change outside their cavity, and precise scheduling may be less consequential.

Although advantages of an early chronotype for great tits are thought to be numerous and activity-onset is accurately timed, these advantages must be counterbalanced by factors that keep their chronotype from extreme earliness. Benefits of an early rise may be limited by food that may not yet be available (Bednekoff \& Krebs, 1995; Sibly, 1975), by females not responding to courtship (Mace, 1986), or by light conditions (Kacelnik, 1979; Thomas et al., 2002). Furthermore, cold night and morning temperatures may add an energetic cost of leaving the roosting site too early in the day (Bednekoff et al., 1994; Krams et al., 2010). To the extent that these factors exert selection pressures, any evolutionary responsiveness of birds requires that timing be consistent within an individual but variable within a population (Lynch \& Walsh, 1998). This was the case in our study population for annual breeding schedules, and selection on timing traits and their heritable components has been shown (Husby et al., 2010; Nussey et al., 2005). In our study on daily timing, we found significant differences between individuals and substantial repeatability of individual schedules, indicating birds show consistent behavior, at least, under laboratory conditions (Figure 3). Repeatability was of comparable magnitude across timing parameters (Table 2), partly because duration of activity and chronotype are related by their derivation to activity-onset and activity-offset. To our knowledge, highly repeatable time patterns of the free-running and entrained clock are a novel finding for animals taken from the wild and all the more important because they indicate that timing might be similarly consistent in the real world where selection takes place. 
Taken together, the observed differences between morning and evening in temperature sensitivity and variability suggest that not chronotype as a whole is subject to selection but rather its temporal components, e.g., onset and end of activity. These components could be differently modified in organisms depending on the general lifestyle of a species. Our inability to detect correlation between chronotype and $\tau$, despite effects of temperature on both parameters, could be related to complex interactions of the circadian clock and chronotype. This interaction can also be influenced by many additional factors, such as light conditions, ambient temperature, food availability, or social context (Beersma et al., 2008; Fleissner \& Fleissner, 2002; Helm \& Visser, 2010). A huge effort is required to examine this in captivity, and it may yield results that are not directly applicable to the situation in the wild. Therefore, data from birds in their natural environment are needed to shed more light on the relationship of $\tau$ and chronotype and their impact on timing, behavior, and survival.

\section{ACKNOWLEDGMENTS}

We thank Christa Mateman for EP analysis, Marylou Aaldering and Floor Petit for animal care taking, and $A b$ and Gilles Wijlhuizen for technical support. Dusty Dowse helped by excellent comments and considerations regarding the circadian data. Thanks to The International Max Planck Research School for Organismal Biology for support. Special thanks go to the three anonymous reviewers for their comments and suggestions, which improved the manuscript considerably.

Declaration of Interest: M.E.V. is supported by a NWOVICI (The Netherlands Organization for Scientific Research) grant and B.H. is supported by the European Social Fund in Baden-Württemberg.

The authors report no conflicts of interest. The authors alone are responsible for the content and writing of the paper.

\section{REFERENCES}

Allebrandt KV, Roenneberg T. (2008). The search for circadian clock components in humans: new perspectives for association studies. Braz. J. Med. Biol. Res. 41:716-721.

Aschoff 1 . (1965). The phase-angle difference in circadian periodicity. In Aschoff J (ed.). Circadian clocks. Amsterdam: North-Holland, 262-276.

Aschoff J. (1979). Circadian rhythms: influences of internal and external factors on the period measured in constant conditions. Z. Tierpsychol. 49:225-249.

Aschoff J, Pohl H. (1978). Phase relations between a circadian rhythm and its zeitgeber within the range of entrainment. Naturwissenschaften $65: 80-84$.

Aschoff J, Wever R. (1962). Über Phasenbeziehungen zwischen biologischer Tagesperiodik und Zeitgeberperiodik. J. Comp. Physiol. 46:115-128
Aschoff J, Wever R. (1966). Circadian period and phase-angle difference in chaffinches (Fringilla coelebs L.). Comp. Biochem. Physiol. 18:397-404

Bednekoff PA, Houston Al. (1994). Avian daily foraging patterns: effects of digestive constraints and variability. Evol. Ecol. 8:36-52.

Bednekoff PA, Krebs JR. (1995). Great Tit fat reserves: effects of changing and unpredictable feeding day length. Funct. Ecol. 9:457-462.

Bednekoff PA, Biebach H, Krebs J. (1994). Great Tit fat reserves under unpredictable temperatures. J. Avian Biol. 25:156-160.

Beersma DGM, van Bunnik BAD, Hut RA, Daan S. (2008). Emergence of circadian and photoperiodic system level properties from interactions among pacemaker cells. J. Biol. Rhythms 23:362-373.

Bertin A, Houdelier C, Richard-Yris M-A, Guyomarc'h C, Lumineau S. (2007). Stable individual profiles of daily timing of migratory rest" lessness in European quail. Chronobiol. Int. 24:253-267.

Brown SA, Kunz D, Dumas A, Westermark PO, Vanselow K, TilmannWahnschaffe A, Herzel H, Kramer A. (2008). Molecular insights into human daily behavior. Proc. Natl. Acad. Sci. U. S. A. 105:1602-1607.

Charmantier A, McCleery RH, Cole LR, Perrins C, Kruuk LEB, Sheldon $B C$. (2008). Adaptive phenotypic plasticity in response to climate change in a wild bird population. Science 320:800-803.

Conover WJ, Iman RL. (1981). Rank transformations as a bridge between parametric and nonparametric statistics. Am. Stat. 35:124-129.

Daan S, Aschoff J. (1975). Circadian rhythms of locomotor activity in captive birds and mammals - their variations with season and latitude. Oecologia 18:269-316.

Daan S, Aschoff I. (1982). Circadian contributions to survival. In Aschoff I, Daan S, Groos GA (eds.). Vertebrate circadian systems: structure and physiology. Berlin: Springer-Verlag, 305-321.

Daan S, Beersma DGM. (2002). Circadian frequency and its variability. In Kumar V (ed.). Biological rhythms. New Delhi: Narosa, 24-37.

Dallmann R, DeBruyne JP, Weaver DR. (2011). Photic resetting and entrainment in CLOCK-deficient mice. J. Biol. Rhythms 26:390-401.

DeCoursey P. (1960). Phase control of activity in a rodent. Cold Spring Harbor Symp. Quant. Biol. 25:49-55.

Dolan AC, Murphy MT, Redmond LJ, Sexton K, Duffield D. (2007). Extrapair paternity and the opportunity for sexual selection in a socially monogamous passerine. Behau. Ecol. 18:985-993.

Enright JT. (1966). Temperature and the free-running circadian rhythm of the house finch. J Comp physiol A Neuroethol Sens Neural Behav Physiol. 18:463-475.

Fleissner G, Fleissner G. (2002). Perception of natural zeitgeber signals In Kumar V(ed.). Biological rhythms. New-Delhi: Narosa, 83-93.

Fleury F, Allemand R, Vavre F, Fouillet P, Bouletreau M. (2000). Adaptive significance of a circadian clock: temporal segregation of activities reduces intrinsic competitive inferiority in Drosophila parasitoids. Proc. Biol. Sci. 267:1005-1010.

Genstat. (1993). Genstat 5 release 3 reference manual. Oxford, UK: Clarendon Press.

Gosler A. (1993). The great tit. London: Hamlyn, 128.

Helm B, Gwinner E. (2005). Carry-over effects of day length during spring migration. J. Ornithol. 146:348-354.

Helm B, Visser ME. (2010). Heritable circadian period length in a wild bird population. Proc. Biol. Sci. 277:3335-3342.

Hinde RA. (1952). The behaviour of the Great tit (Parus major) and some other related species. Behav. Suppl. 2: III, V-X, 1-201.

Husby A, Nussey DH, Visser ME, Wilson AI, Sheldon BC, Kruuk LEB. (2010). Contrasting patterns of phenotypic plasticity in reproductive traits in two great tit (Parus major) populations. Evolution 64:2221-2237

Kacelnik A. (1979). The foraging efficiency of great tits (Parus major L.) in relation to light intensity. Anim. Behav. 27:237-241.

Kacelnik A, Krebs JR. (1982). The dawn chorus in the great tit (Parus major): proximate and ultimate causes. Behaviour 83:287-309.

Kempenaers B, Borgström P, Loës P, Schlicht E, Valcu M. (2010). Artificial night lighting affects dawn song, extra-pair siring success, and lay date in songbirds. Curr. Biol. 20:1735-1739.

Krams I, Cirule D, Suraka V, Krama T, Rantala MJ, Ramey G. (2010). Fattening strategies of wintering Great tits support the optimal 
body mass hypothesis under conditions of extremely low ambient temperature. Funct. Ecol. 24 172-177.

Kronfeld-Schor N, Dayan T. (2003). Partitioning of time as an ecological resource. Annu. Rev. Ecol. Evol. Syst. 34:153-181.

Lessells CM, Boag PT. (1987). Unrepeatable repeatabilities: a common mistake. The Auk 104:116-121.

Lynch M, Walsh B. (1998). Genetics and analysis of quantitative traits. Sunderland, MA: Sinauer, 980 .

Mace R. (1986). Importance of female behaviour in the dawn chorus. Anim. Behav. 34:621-622.

Menaker M. (2006). Circadian organization in the real world. Proc. Natl. Acad. Sci. U. S. A. 103:3015-3016.

Merrow M, Spoelstra K, Roenneberg T. (2005). The circadian cycle: daily rhythms from behaviour to genes. EMBO Rep. 6:930-935.

Moore D, Doherty P. (2009). Acquisition of a time-memory in forager honey bees. J. Comp. Physiol. Sens. Neu. Behav. Physiol. 195:741-751

Murphy MT, Sexton K, Dolan AC, Redmond LJ. (2008). Dawn song of the Eastern Kingbird: an honest signal of male quality? Anim. Behav. 75:1075-1084.

Natale V, Di Milia L. (2011). Season of birth and morningness: comparison between the northern and southern hemisphere. Chronobiol. Int. 28:727-730.

Nussey DH, Postma E, Gienapp P, Visser ME. (2005). Selection on heritable phenotypic plasticity in a wild bird population. Science 310:304-306.

Poesel A, Kunc HP, Foerster K, Johnsen A, Kempenaers B. (2007). Early birds are sexy: male age, dawn song and extra-pair paternity in Blue tits, Cyanistes (formerly Parus) caeruleus. Anim. Behav. 72:531-538.

Pohl H. (1968). Einfluß der Temperatur auf die freilaufende circadiane Aktivitätsperiodik bei Warmblütern. J. Comp. Physiol. Sens. Neu. Behav. Physiol. 58:364-380.

Pohl H. (1974). Interaction of effects of light, temperature and season on the circadian period of Carduelis flammea. Naturwissenschaften 61:406-407.

Portaluppi F, Smolensky MH, Touitou Y. (2010). Ethics and methods for biological rhythm research on animals and human beings. Chronobiol. Int. 27:1911-1929.

R Development Core Team. (2012). R: a language and environment for statistical computing. Vienna, Austria: R Foundation for Statistical Computing, http://www.R-project.org/ Accessed 30 March 2012.

Redlin U. (2001). Neural basis and biological function of masking by light in mammals: suppression of melatonin and locomotor activity. Chronobiol. Int. 18:737-758.
Rensing L, Ruoff P. (2002). Temperature effect on entrainment, phase shifting, and amplitude of circadian clocks and its molecular bases. Chronobiol. Int. 19:807-864.

Roenneberg T, Merrow M. (2007). Entrainment of the human circadian clock. Cold Spring Harbor Symp. Quant. Biol. 72:293-299.

Roenneberg T, Kuehnle T, Juda M, Kantermann T, Allebrandt $\mathrm{K}$, Gordijn M, Merrow M. (2007). Epidemiology of the human circadian clock, Sleep Med. Rev. 11:429-438.

Ruf T. (1999). The Lomb-Scargle periodogram in biological rhythm research: analysis of incomplete and unequally spaced timeseries. Biol. Rhythm Res. 30:178-201.

Ruoff P, Rensing L. (2004). Temperature effects on circadian clocks. $J$. Therm. Biol. 29:445-456.

Sakai T, Ishida N. (2001). Time, love and species. Neuro. Endocrinol. Lett. 22:222-228

Schaper SV, Dawson AS, Sharp PJ, Gienapp P, Caro SP, Visser ME. (2012). Increasing temperature, not mean temperature, is a cue for avian timing of reproduction. Am. Nat. 179:E55-E69.

Shimizu T, Masaki S. (1997). Geographical and species variation in circadian rhythm parameters in nemobiine crickets. Physiol. Entomol. 22:83-93.

Sibly R. (1975). How incentive and deficit determine feeding tendency. Anim. Behav. 23(Part 2):437-446.

Spoelstra K. (2010). ChronoShop 1.01. http://www.hutlab.nl/Accessed 10 October 2011.

Strang-Karlsson S, Kajantie E, Pesonen A-K, Räikkönen K, Hovi P, Lahti I, Heinonen K, Järvenpää A-L, Eriksson JG, Andersson S, Paavonen J. (2010). Morningness propensity in young adults born prematurely: the Helsinki study of very low birth weight adults. Chronobiol. Int. 27:1829-1842.

Sweeney BM, Hastings JW. (1960). Effects of temperature upon diurnal rhythms. Cold Spring Harbor Symp. Quant. Biol. 25:87-104.

Thomas RJ, Székely T, Cuthill IC, Harper DG, Newson SE, Frayling TD, Wallis PD. (2002). Eye size in birds and the timing of song at dawn. Proc. Biol. Sci. 269:831-837.

Vivanco P, Rol MÁ, Madrid JA. (2010). Temperature cycles trigger noc-turnalism in the diurnal homeotherm Octodon degus. Chronobiol. Int. 27:517-534.

Wyse CA, Coogan AN, Selman C, Hazlerigg DG, Speakman JR. (2010). Association between mammalian lifespan and circadian freerunning period: the circadian resonance hypothesis revisited. Biol. Lett. 6:696-698.

Ydenberg RC. (1984). The conflict between feeding and territorial defence in the great tit. Behav. Ecol. Sociobiol. 15:103-108. 
SUPPLEMENTARY TABLE I. Response of circadian period length to a $10^{\circ} \mathrm{C}$ increase of ambient temperature in various species (adapted from Aschoff, 1979; Sweeney \& Hastings, 1960)

\begin{tabular}{lllll}
\hline Species & Active period & Thermoregulation & Q10 \\
\hline Carduelis flammea & Day & Endotherm & .99 & Source \\
Carpodacus mexicanus & Day & Endotherm & .99 & En (1974) \\
Fringilla coelebs & Day & Endotherm & .99 & Pohl (1968) \\
Macaca nemestrina & Day & Endotherm & 1.01 & Tokura \& Aschoff (1983) \\
Drosophila pseudoobscura & Day & Ectotherm & 1.02 & Pittendrigh (1954) \\
Lacerta sicula & Day & Ectotherm & 1.02 & Hoffmann (1957) \\
Uca pugnax & Day & Ectotherm & 1.0 & Brown \& Webb (1948) \\
Euglena gracilis & Day & Ectotherm & $1.01-1.1$ & Bruce \& Pittendrigh (1956) \\
Glis glis & Night & Endotherm & 1.03 & Pohl (1968) \\
Perognathus longimembris & Night & Endotherm & 1.01 & Lindberg et al. (1971) \\
Peromyscus leucopus & Night & Endotherm & $1.1-1.4$ & Rawson (1959) \\
Myotis lucifucus & Night & Endotherm & 1.4 & Rawson (1959) \\
Thamnophis radix & Night & Ectotherm & 1.04 & Heckrotte (1975) \\
Admetus pumilio & Night & Ectotherm & 1.02 & Beck (1972) \\
Periplaneta americana & Night & Ectotherm & 1.06 & Bünning (1958) \\
Neurospora & Night & Ectotherm & Pittendrigh et al. (1959) \\
Gonyaulax polyedra & Night & Ectotherm & Hastings \& Sweeney (1957) \\
\hline
\end{tabular}

${ }^{\dagger}$ The majority of references cited can be found in these publications and are listed below.

\section{REFERENCES}

Aschoff J. (1979). Circadian rhythms: influences of internal and external factors on the period measured in constant conditions. Z. Tierpsychol. 49:225-249.

Beck L. (1972). Zur Tagesperiodik der Laufaktivität von Admetus pumilio C. Koch (Arach., Amblypygi) aus dem neotropischen Regenwald. II Oecologia 9:65-102.

Brown FAJ, Webb HM. (1948). Temperature relations of an endogenous daily rhythmicity in the Fiddler Crab, Uca. Physiol. Zool. 21:371-381.

Bruce VG, Pittendrigh CS. (1956). Temperature independence in a unicellular "clock". Proc. Natl. Acad. Sci. U. S. A. 42:676-682.

Bünning E. (1958). Über den Temperatureinfluss auf die endogene Tagesrhythmik besonders bei Periplaneta americana. Biol. Zentbl. 77:141-152.

Enright JT. (1966). Temperature and the free-running circadian rhythm of the house finch. Comp. Biochem. Physiol. 18:463-475.

Hastings JW, Sweeney BM. (1957). On the mechanism of temperature independence in a biological clock. Proc. Natl. Acad. Sci. U. S. A. 43:804-811.

Heckrotte C. (1975). Temperature and light effects on the circadian rhythm and locomotory activity of the plains garter snake (Thamnophis radix hayendi). J. Interdiscipl. Cycle Res, 6:279-289.

Hoffmann K. (1957). Über den Einfluß der Temperatur auf die Tagesperiodik bei einem Poikilothermen. Naturwissenschaften 44:358-358.
Lindberg RG, Gambino JI, Hayden P. (1971). Circadian periodicity of resistance to ionizing radiation in the pocket mouse. In Menaker M (ed.). Biochronometry; proceedings of a symposium Friday Harbor, Washington, Washington DC, September 1969. National Academy of Sciences, pp. 169-185.

Pittendrigh CS. (1954). On temperature independence in the clock system controlling emergence time in Drosophila. Proc. Natl. Acad. Sci. U. S. A. 40:1018-1029.

Pittendrigh CS, Bruce VG, Rosensweig NS, Rubin ML. (1959). Biological clock in Neurospora. Nature 184:169-170.

Pohl H. (1968). Einfluß der Temperatur auf die freilaufende circadiane Aktivitätsperiodik bei Warmblütern. J. Comp. Physiol. Sens. Neu. Behav. Physiol. 58:364-380.

Pohl H. (1974). Interaction of effects of light, temperature and season on the circadian period of Carduelis flammea. Naturwissenschaften 61:406-407.

Rawson KS. (1959). Experimental modification of mammalian endogenous activity rhythms. In RB Withrow (ed.). Photoperiodism and related phenomena in plants and animals. Washington, DC: American Association for the Advancement of Science, pp 791-800.

Sweeney BM, Hastings JW. (1960). Effects of temperature upon diurnal rhythms. Cold Spring Harbor Symp. Quant. Biol. 25:87-104.

Tokura H, Aschoff J. (1983). Effects of temperature on the circadian rhythm of pig-tailed macaques Macaca nemestrina. Am. J. Physiol. 245:R800-R804. 


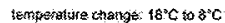

is

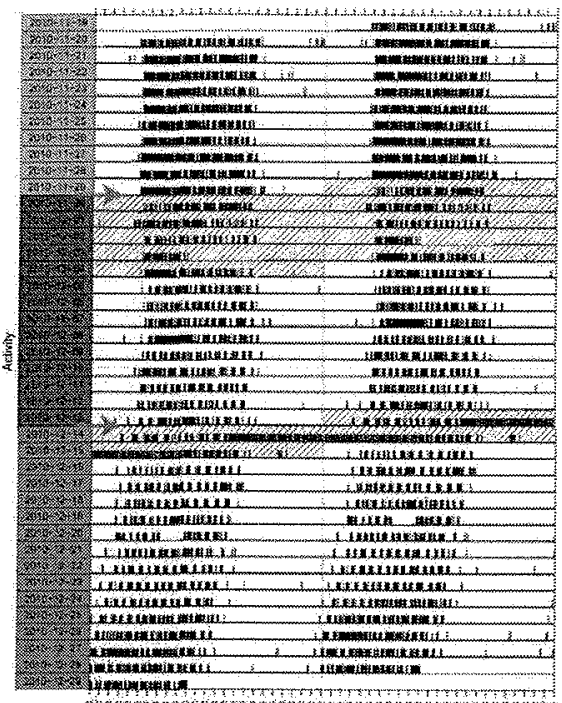

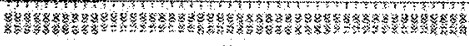

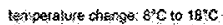

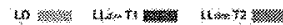

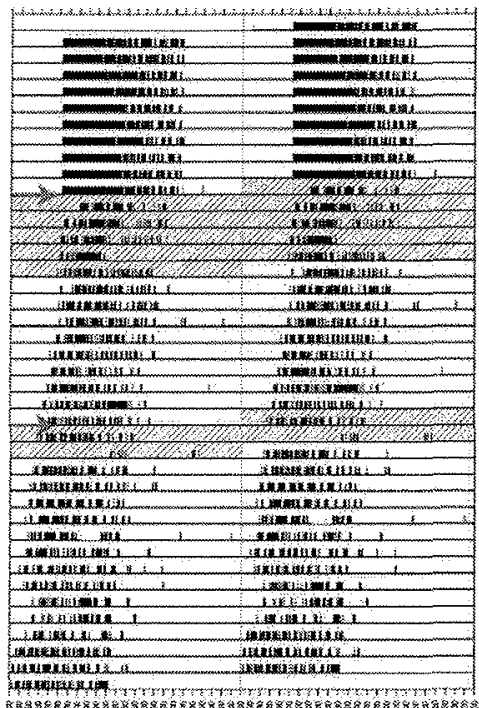

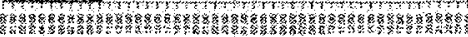

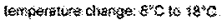

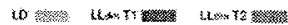

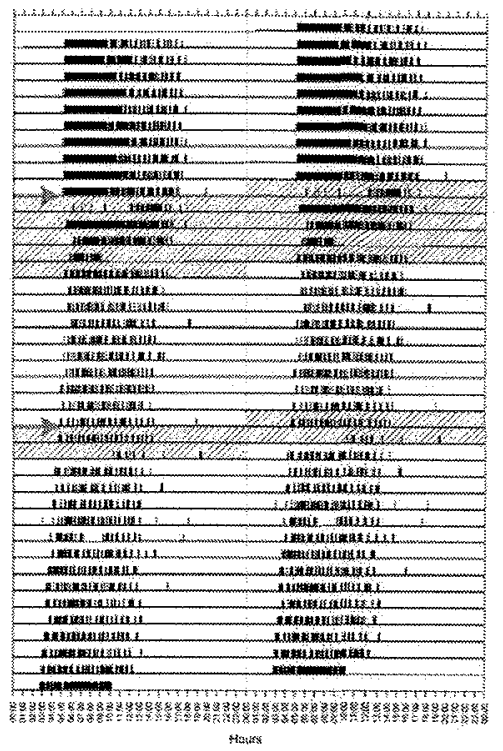

SUPPLEMENTARY FIGURE 1. Actograms (double-plot) of three individuals throughout the experiment. Hatched areas indicate days excluded from analysis. Arrows indicate treatment changes, i.e., from $L D$ to $\mathrm{LL}_{\mathrm{dim}}$ (upper arrow) and from $8^{\circ} \mathrm{C}$ to $18^{\circ} \mathrm{C}$ or $18^{\circ} \mathrm{C}$ to $8^{\circ} \mathrm{C}$, respectively (lower arrow). Left actogram: $18^{\circ} \mathrm{C}$ to $8^{\circ} \mathrm{C}$, $\mathrm{T}$ accelerates. Middle actogram: $8^{\circ} \mathrm{C}$ to $18^{\circ} \mathrm{C}$, $\mathrm{T}$ decelerates. Right actogram: $18^{\circ} \mathrm{C}$ to $8^{\circ} \mathrm{C}$, $\mathrm{T}$ unchanged. 